\section{Editorial}

REV EXP MED 2019;5(3).

Julio - Septiembre

\title{
Escribir la ciencia, un desafío impostergable
}

\section{Writing science, a challenge that cannot be postponed}

\section{Verónica Chumacero-Ancajima ${ }^{1, a}$}

¿Por qué es importante que los profesionales se capaciten en escritura científica? En las siguientes líneas reflexionamos sobre cuán necesario es potenciar las habilidades de redacción científica en los distintos agentes que participan en la producción nacional de conocimiento científico.

En el contexto académico se exige el dominio de la comunicación científica. El alumno desde que se inserta en el mundo universitario debe adoptar un lenguaje y estilo académicos tanto en sus textos orales como escritos; el discente debe conocer y dominar la elaboración de monografías, ensayos, informes, proyectos, resúmenes, reseñas... y, por supuesto, como culminación de su trayectoria académica, debe conseguir redactar una tesis, que lo consagrará como profesional.

Pero tal competencia comunicativa no se logra afianzar en todos los alumnos, ya que en el transcurso de la carrera universitaria ellos no siempre se han tomado en serio, y con la disciplina necesaria, las tareas de leer y escribir. A todo esto se añade, que una vez que egresan se pueden sumar otros factores que retrasan al alumno en la consecución de la ansiada tesis, desde económicos, familiares, laborales hasta personales. Una vez que se pierde el ritmo de la investigación y de la escritura, encontrar el camino se vuelve más difícil. Esta pausa lo único que hace en el egresado es postergar el fortalecimiento de sus habilidades comunicativas para la redacción final de la tesis.

Para el alumno universitario la tesis se convierte en el gran reto académico y en su construcción tiene que demostrar todas las habilidades comunicativas que le permitan culminar con éxito este objetivo. El problema radica en que no todos los alumnos alcanzan la seguridad necesaria para escribir este tipo de texto y se enfrentan ante la frustración y ante una imperiosa necesidad de buscar caminos que lo ayuden a concluir con éxito su etapa universitaria.

En cuanto al posgrado, se debe mencionar que la tasa de graduados de los programas de maestría y doctorado a nivel nacional aún es bajo. Precisemos que los estándares de acreditación, tanto para pregrado y posgrado, se miden por la tasa de graduados. Por tal motivo, se hace necesario presentar espacios para que conozcan, adquieran o fortalezcan todas las debilidades que presentan los maestrantes y doctorandos en la construcción de la tesis, que es un texto expositivo argumentativo que exige el desarrollo de un buen nivel de lenguaje científico basado en evidencias.

Por otro parte, tanto los egresados de pregrado como postgrado tienen y confían en el acompañamiento cercano de su asesor de tesis. En ese sentido, el profesor-asesor no solo debe poseer conocimientos de investigación sino también de redacción académico científica, debe poseer la preparación en este campo para ser un apoyo eficaz y corregir con rigurosidad los avances de los tesistas. Es el asesor quien garantiza que el alumno ha logrado comunicarse académicamente mediante la tesis correspondiente. Además, en él recaen responsabilidades importantes, como dar pase a la sustentación y a la publicación de la tesis en el repositorio bibliográfico de la institución, y el hecho de contribuir y motivar a que el alumno canalice su investigación por el mejor medio de difusión científica. Todos estos encargos exigen en el asesor una profunda preparación en el lenguaje académico científico y su proceso de escritura. En nuestra localidad son pocos los profesores que brindan servicio de asesoría que hayan sido capacitados en escritura de textos académicos y científicos. Generalmente, manejan el proceso de investigación y no se comprometen o se desentienden de la correcta plasmación de las ideas en el papel.

La investigación es un reto y la razón de ser de toda institución académica. Y la investigación no se entiende sin la publicación de sus resultados. En ese sentido, es que todo profesional que se dedique a esta tarea necesita pautas para potenciar sus habilidades en la escritura y publicación de artículos

\footnotetext{
1. Universidad Católica Santo Toribio de Mogrovejo, Chiclayo, Perú.
}

correo: vchumacero.investigaciones@gmail.com

a. Magíster en Filología Hispánica y magíster en Lengua Española. 
científicos en revistas de alto impacto. Si un centro de investigación logra que sus profesionales hagan de la publicación una prioridad, un hábito, contribuirá con el desarrollo de la ciencia y de la sociedad, y, por ende, crecerá en prestigio y conseguirá cumplir los estándares exigidos por las entidades acreditadoras.

En el Perú esto es una necesidad impostergable, mientras lo pensamos... los buscadores de literatura científica ya nos están arrojando nuevos artículos más que leer y documentar. La ciencia avanza a pasos agigantados, solo la contribución de países como Brasil, México, Colombia y Chile es realmente superior y notoria. Al respecto, cabe preguntarnos ¿cuánto aporta el Perú a la ciencia?, y específicamente ¿cuánto aportas tú desde tu área científica a su consolidación? EI Perú necesita de profesionales éticos que reflexionen sobre su quehacer científico, que coloquen sus resultados sobre un papel y los saquen a la luz mediante una publicación de trascendencia internacional. No podemos postergarlo más. 